University of Wollongong

Research Online

Faculty of Engineering and Information

Faculty of Engineering and Information

Sciences - Papers: Part A

Sciences

January 2014

Effect of composition and thermo-mechanical processing on microstructure development in $\mathrm{Ni}-30 \mathrm{Fe}-\mathrm{Nb}-\mathrm{C}$ model alloys

Parvez Mannan

University of Wollongong, pm999@uowmail.edu.au

Andrii Kostryzhev

University of Wollongong, andrii@uow.edu.au

Elena V. Pereloma

University of Wollongong, elenap@uow.edu.au

Follow this and additional works at: https://ro.uow.edu.au/eispapers

Research Online is the open access institutional repository for the University of Wollongong. For further information contact the UOW Library: research-pubs@uow.edu.au 


\title{
Effect of composition and thermo-mechanical processing on microstructure development in Ni-30Fe-Nb-C model alloys
}

\author{
Abstract \\ The unavoidable phase transformation upon cooling makes a direct observation of austenite \\ microstructure impossible. One of the methods to investigate the high temperature condition of austenite \\ is to use a model alloy, which would not transform to martensite on quenching. In the present work the \\ recrystallisation and grain growth of austenite during thermo-mechanical processing (TMP) were studied \\ for three Ni-30Fe-Nb-C alloys containing $0.33,0.85$ and $1.42 \mathrm{wt} \% \mathrm{Nb}$. The austenite microstructures were \\ characterised using optical and scanning electron microscopy, and energy dispersive X-ray spectroscopy. \\ The austenite recrystallisation kinetics was investigated with respect to the precipitate distribution \\ variations. A relative strength of the grain boundary pinning effect from solute $\mathrm{Nb}$ and precipitated \\ particles is discussed.

\section{Keywords} \\ composition, thermo, mechanical, processing, microstructure, effect, development, model, ni, 30fe, nb, c, \\ alloys

\section{Publication Details} \\ Mannan, P., Kostryzhev, A. G. \& Pereloma, E. V. (2014). Effect of composition and thermo-mechanical \\ processing on microstructure development in Ni-30Fe-Nb-C model alloys. Advanced Materials Research, \\ 922 475-480.
}




\title{
Effect of Composition and Thermo-mechanical Processing on Microstructure Development in Ni-30Fe-Nb-C Model Alloys
}

\author{
Parvez Mannan ${ }^{1, a}$, Andrii G. Kostryzhev ${ }^{1, b}$ and Elena V. Pereloma ${ }^{1,2, c}$ \\ ${ }^{1}$ School of Mechanical, Materials and Mechatronics Engineering, University of Wollongong, \\ Wollongong 2522, Australia \\ ${ }^{2}$ UOW Electron Microscopy Centre, University of Wollongong, Australia \\ apm999@uowmail.edu.au, bandrii@uow.edu.au, celenap@uow.edu.au
}

Keywords: thermo-mechanical processing, Nb precipitation, recrystallisation, grain growth

\begin{abstract}
The unavoidable phase transformation upon cooling makes a direct observation of austenite microstructure impossible. One of the methods to investigate the high temperature condition of austenite is to use a model alloy, which would not transform to martensite on quenching. In the present work the recrystallisation and grain growth of austenite during thermomechanical processing (TMP) were studied for three Ni-30Fe-Nb-C alloys containing $0.33,0.85$ and $1.42 \mathrm{wt} \% \mathrm{Nb}$. The austenite microstructures were characterised using optical and scanning electron microscopy, and energy dispersive X-ray spectroscopy. The austenite recrystallisation kinetics was investigated with respect to the precipitate distribution variations. A relative strength of the grain boundary pinning effect from solute $\mathrm{Nb}$ and precipitated particles is discussed.
\end{abstract}

\section{Introduction}

Grain refinement usually results in simultaneously high strength and toughness of metallic materials [1]. A fundamental step to refine the ferrite grain size in steels is to carefully control the austenite recrystallisation kinetics during TMP. Although a significant amount of research was carried out in this field, a direct observation of the high temperature microstructure is a challenge due to the phase transformation upon cooling to room temperature. Lower temperature transformation products (martensite, ferrite) obscure the high temperature features of microstructure (prior austenite grains and microalloying element precipitates) and complicate investigation of dynamic recrystallisation. To overcome this challenge, $\mathrm{Ni}-30 \% \mathrm{Fe}$ can be used as a model alloy for studying the behaviour of austenite at high temperature [2-4]. This model alloy does not undergo phase transformation upon quenching (remains austenitic at room temperature) and has almost similar stacking fault energy and crystallographic texture evolution to those of carbon steel [4].

Niobium is known to retard austenite recrystallisation and refine grain size via the solute drag and grain boundary pinning effects [5-9]. Large $\mathrm{Nb}$-rich particles may enhance sub-grain structure development (formation of twins and deformation bands), which in steels may lead to an increase in the number of ferrite nucleation sites and ferrite grain refinement $[10,11]$. In this original paper we study the $\mathrm{NbC}$ particle precipitation and austenite grain structure development during TMP of three Ni-30Fe-Nb-C alloys. The effect of alloy composition on the particle size distribution, recrystallisation kinetics and grain growth rate are discussed.

\section{Material and experimental techniques}

Three Ni-30Fe-Nb-C (wt.\%) alloys (Table 1) in the form of $15 \mathrm{~mm}$ thick hot rolled plates were produced and provided by Prof. Hatem Zurob, McMaster University, Canada. NbC dissolution temperatures were calculated to be 976,1196 and $1355^{\circ} \mathrm{C}$ for alloys L, M and H respectively [12]. The plates were cut to standard size samples $(20 \mathrm{~mm} \times 15 \mathrm{~mm} \times 10 \mathrm{~mm})$ for TMP simulation in Gleeble 3500. Prior to the main TMP program the recrystallisation stop temperatures, $\mathrm{T}_{\mathrm{nr}}$, for the three alloys were determined using analysis of the stress-strain curves obtained during multi-hit compression testing in the temperature range of $1100-700{ }^{\circ} \mathrm{C}$. The $\mathrm{T}_{\mathrm{nr}}$ temperatures were found to be $950, \sim 1000$ and $1040{ }^{\circ} \mathrm{C}$ for alloys $\mathrm{L}, \mathrm{M}$ and $\mathrm{H}$ respectively. The main TMP schedule included 
(Fig. 1): heating at $1250{ }^{\circ} \mathrm{C}$ for $300 \mathrm{~s}$ followed by either water quenching or roughing deformation at $1250{ }^{\circ} \mathrm{C}$ up to 0.3 strain at $0.1 \mathrm{~s}^{-1}$ strain rate; finishing deformation at $1075^{\circ} \mathrm{C}$ up to 1.2 strain at $0.1 \mathrm{~s}^{-1}$ strain rate; followed by either water quenching or holding at $1075{ }^{\circ} \mathrm{C}$ during $300 \mathrm{~s}$ and water quenching.

Table 1 Chemical compositions of the studied model alloys $(\% \mathrm{wt})$

\begin{tabular}{|c|c|c|c|c|}
\hline Alloy Type & $\mathrm{Ni}$ & $\mathrm{Fe}$ & $\mathrm{Nb}$ & $\mathrm{C}$ \\
\hline $\mathrm{L}$ & 69.7 & 29.8 & 0.331 & 0.040 \\
\hline $\mathrm{M}$ & 69.2 & 29.7 & 0.851 & 0.114 \\
\hline $\mathrm{H}$ & 68.8 & 29.5 & 1.420 & 0.187 \\
\hline
\end{tabular}

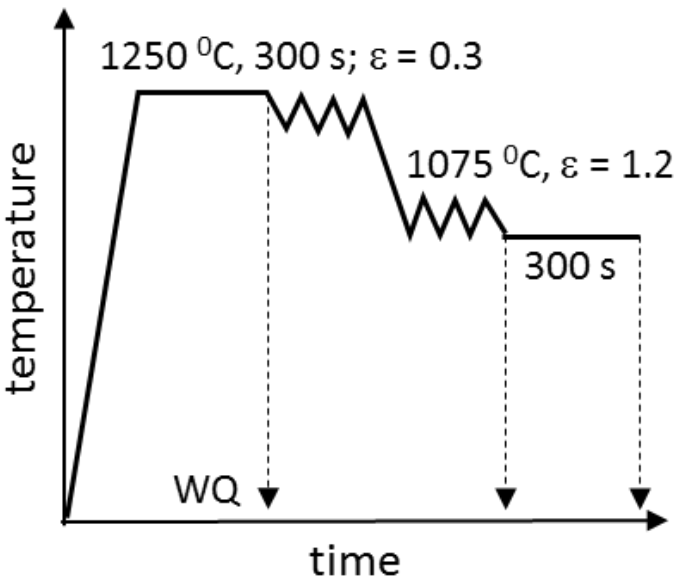

Fig. 1 Schematic diagram of the TMP.

The heating and roughing deformation temperature of $1250{ }^{\circ} \mathrm{C}$ was chosen to be above the $\mathrm{NbC}$ dissolution temperatures in alloys $\mathrm{L}$ and $\mathrm{M}$, which allowed to assume absence of strain induced precipitation during roughing in these alloys. The finishing deformation temperature of $1075{ }^{\circ} \mathrm{C}$ was chosen to be above $\mathrm{T}_{\mathrm{nr}}$ in alloy $\mathrm{H}$, which assured development of dynamic recrystallisation (DRX) during finishing deformation in all the three alloys. After TMP the samples were cut, polished and etched using a solution of ferric chloride $\left(\mathrm{FeCl}_{3}\right)$ and hydrochloric acid $(\mathrm{HCl})$ in water. Optical microscopy of grain structures was carried out using Leica DMRM microscope equipped with Leica Application Suite (LAS) 4.0.0 image processing software. For determination of the grain size distributions about 500 grains were analysed for each TMP condition using Leica Grain Expert software. Imaging of NbC precipitates was carried out using JEOL 7001F FEG scanning electron microscope (SEM). For determination of the particle size distributions 270 700 particles were measured for each TMP condition. Energy dispersive X-ray spectroscopy (EDS) of precipitates was carried out using AZtec 2.0 Oxford SEM EDS system. For determination of the particle compositions about 20 particles were analysed for each TMP condition. Vickers microhardness was measured using Struers DuraScan testing machine.

\section{Results}

TMP and optical microscopy. The average grain size after reheating at $1250^{\circ} \mathrm{C}$ decreased from $\sim 500$ $\mu \mathrm{m}$ in alloy L to $90 \mu \mathrm{m}$ in alloy $\mathrm{M}$ and to $40 \mu \mathrm{m}$ in alloy $\mathrm{H}$, i.e. with an increase in Nb content (Figs. 2,a-c). The average grain size after finishing deformation did not vary significantly with $\mathrm{Nb}$ content (Fig. 2,d) and was measured to be $19 \mu \mathrm{m}$ in alloy $\mathrm{L}, 18 \mu \mathrm{m}$ in alloy $\mathrm{M}$ and $22 \mu \mathrm{m}$ in alloy $\mathrm{H}$. During holding for $300 \mathrm{~s}$ the grain growth took place in all the three alloys (Fig. 2,e). However, it was less pronounced in alloys $\mathrm{M}$ and $\mathrm{H}$ (the average grain size after holding 27 and $31 \mu \mathrm{m}$ respectively) compared to alloy $\mathrm{L}(92 \mu \mathrm{m})$.

The flow curves of finishing deformation showed a maximum of stress followed by a softening region for all three alloys (Fig. 3), which is a typical stress-strain behaviour during DRX. Critical and peak stress values of DRX increased from alloy L (101 and $105 \mathrm{MPa}$ ) to M (107 and $114 \mathrm{MPa}$ ) to $\mathrm{H}(127$ and $130 \mathrm{MPa})$, i.e. with an increase in $\mathrm{Nb}$ content. Absence of a flattened region on the stress-strain curves indicates incomplete DRX for the studied TMP conditions.

SEM of precipitates. In alloy L the SEM imaging and SEM-EDS did not reveal presence of $\mathrm{NbC}$ particles for all the studied TMP conditions, which is obviously due to the processing temperatures being above the particle dissolution temperature $\left(976^{\circ} \mathrm{C}\right)$ in this alloy. 

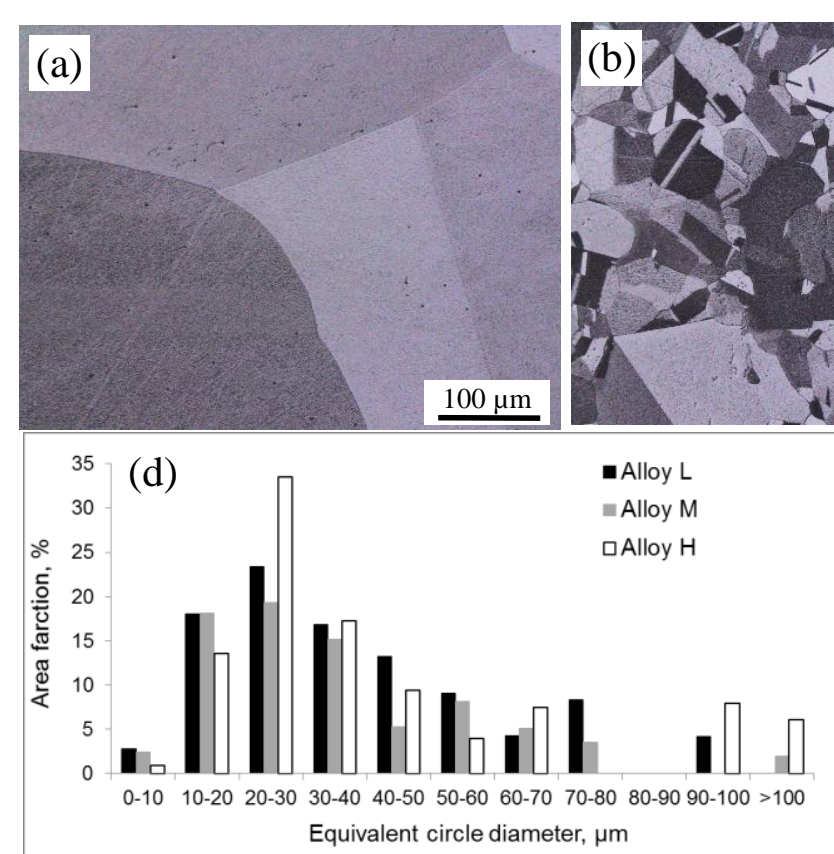

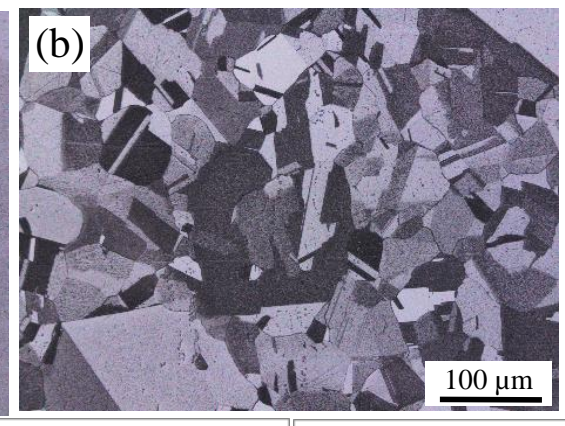

(e)

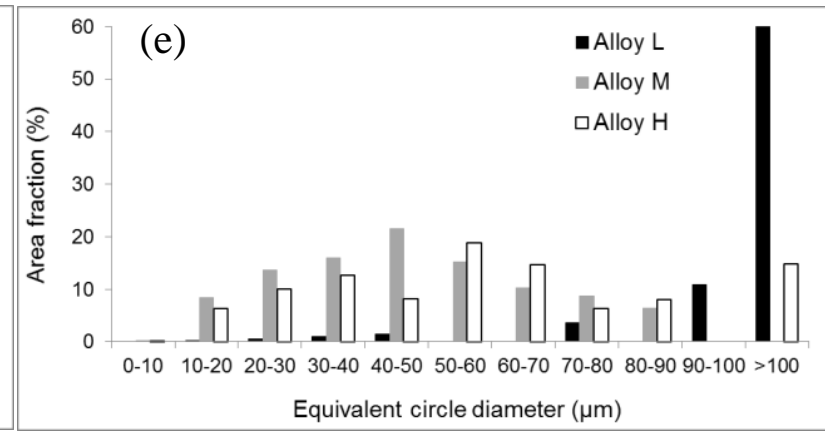

Fig. 2 Optical micrographs showing the grain structure in alloys (a) L, (b) M and (c) $\mathrm{H}$ after heating; (d) and (e) grain size distributions after finishing deformation and $300 \mathrm{~s}$ holding respectively.

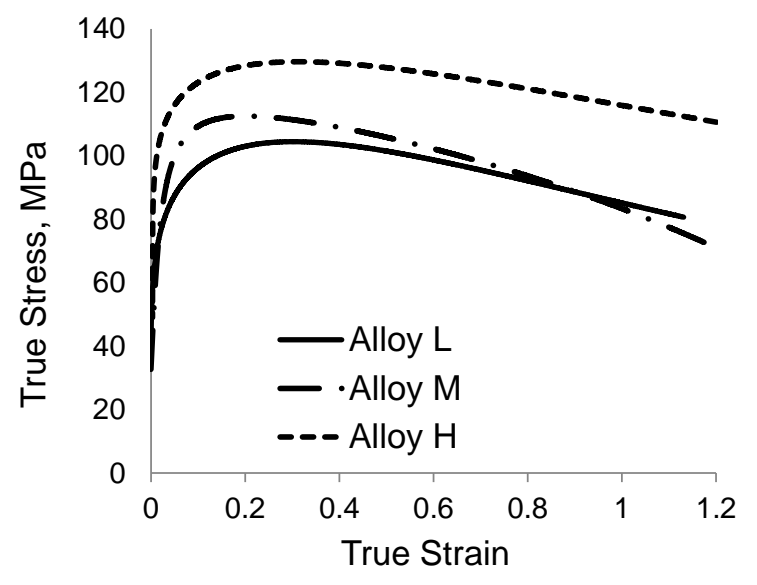

Fig. 3 Stress-strain curves obtained during finishing deformation.
However $36-140 \mathrm{~nm} \mathrm{Fe}_{3} \mathrm{C}$ particles of spherical shape precipitated in alloy $\mathrm{L}$ during holding after finishing deformation (Fig. 4). In alloys $\mathrm{M}$ and $\mathrm{H}$ the $40-5000 \mathrm{~nm} \mathrm{NbC}$ precipitates of spherical, ellipsoidal and rectangular shape were observed for all the studied TMP conditions (Fig. 5). Heating did not result in full dissolution of $\mathrm{NbC}$ particles in alloy $\mathrm{H}$ (Table 2), due to the reheating temperature $\left(1250{ }^{\circ} \mathrm{C}\right)$ being below the particle dissolution temperature $\left(1355{ }^{\circ} \mathrm{C}\right)$ in this alloy. In alloy $\mathrm{M}$ almost all the $\mathrm{NbC}$ particles dissolved during reheating, due to the reheating temperature $\left(1250{ }^{\circ} \mathrm{C}\right)$ being above the particle dissolution temperature $\left(1196^{\circ} \mathrm{C}\right)$ in this alloy.
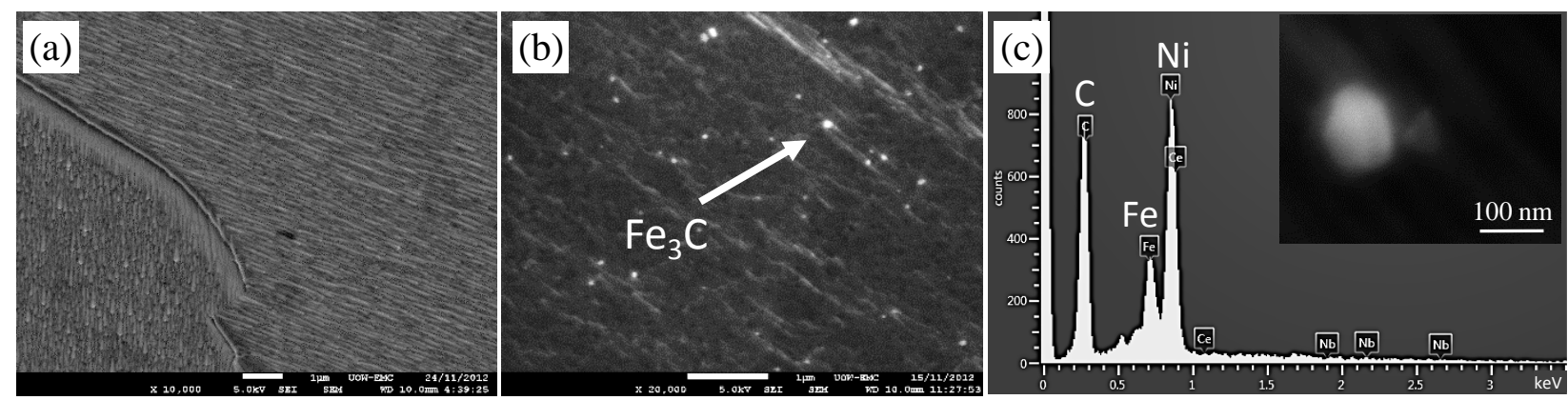

Fig. 4 SEM micrographs of alloy $\mathrm{L}$ (a) after finishing deformation showing absence of $\mathrm{Nb}$ precipitation and (b) after $300 \mathrm{~s}$ holding at $1075^{\circ} \mathrm{C}$ showing $\mathrm{Fe}_{3} \mathrm{C}$ precipitation; (c) a typical EDS spectrum of $\mathrm{a} \mathrm{Fe}_{3} \mathrm{C}$ particle observed in alloy $\mathrm{L}$.

After deformation, the particle number density significantly increased and the average particle diameter decreased in alloy $M$ (Table 2 and Fig. 6), which indicate strain-induced precipitation. In alloy $\mathrm{H}$ the particle number density also increased after deformation, however to a significantly 
lower extent compared to alloy $\mathrm{M}$. The average particle diameter in alloy $\mathrm{H}$ increased after deformation, in contrast to alloy $\mathrm{M}$. These indicate a particle growth in alloy $\mathrm{H}$, which takes place simultaneously with precipitation of new particles. During holding after deformation the particle number density decreased and the average particle diameter increased in both alloys, which indicate the particle growth.
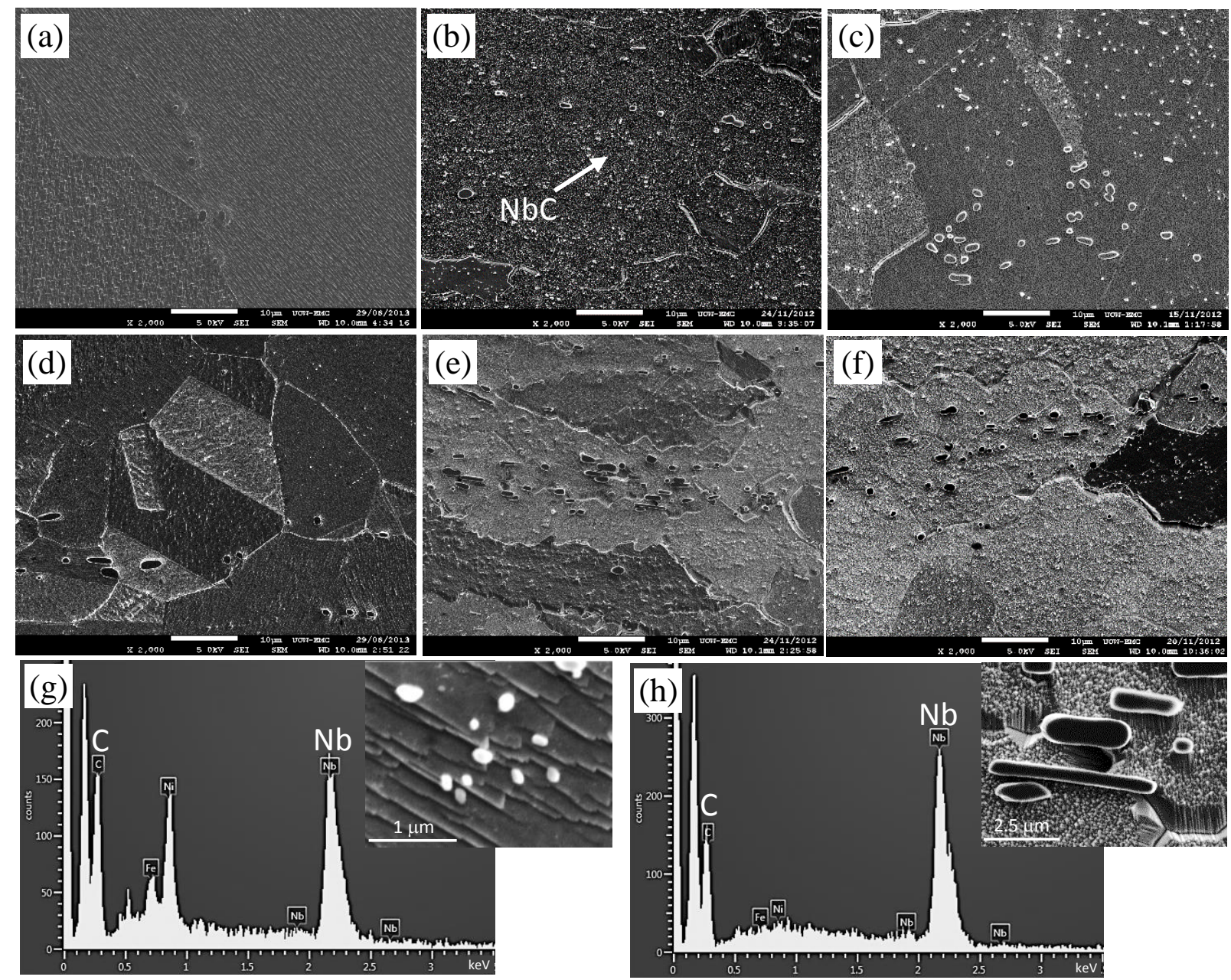

Fig. 5 Representative SEM micrographs showing NbC particles in alloy (a - c) M and (d - f) H after $(\mathrm{a}, \mathrm{d})$ holding at $1250^{\circ} \mathrm{C},(\mathrm{b}, \mathrm{e})$ finishing deformation and $(\mathrm{c}, \mathrm{f})$ holding at $1075^{\circ} \mathrm{C} ;(\mathrm{g})$ and $(\mathrm{h})$ are typical EDS spectra of small and large particles respectively.

\section{Discussion}

After holding at $1250^{\circ} \mathrm{C}$ the grain size decreased from alloy $\mathrm{L}$ to $\mathrm{M}$ to $\mathrm{H}$, i.e. with an increase in the microalloying element content and the $\mathrm{NbC}$ number density (Table 2). This indicates a decrease in the grain growth rate following an increase in the grain boundary pinning effect from solute atoms and precipitates, and corresponds to earlier data observed in microalloyed steels $[13,14]$. In particular, with an increase in the microalloying element content by $[\mathrm{Nb}+\mathrm{C}]_{\mathrm{M}} /[\mathrm{Nb}+\mathrm{C}]_{\mathrm{L}}=2.6$ times from alloy $\mathrm{L}$ to $\mathrm{M}$ the grain size decreased by about 5.5 times. With an increase in the microalloying element content by $[\mathrm{Nb}+\mathrm{C}]_{\mathrm{H}} /[\mathrm{Nb}+\mathrm{C}]_{\mathrm{L}}=4.3$ times from alloy $\mathrm{L}$ to $\mathrm{H}$ the grain size decreased by about 12.5 times. Thus, a variation in the grain boundary pinning effect during grain growth was more than 2 times larger than a variation in the microalloying element content leading to this effect.

After deformation the observed grain size was almost similar in all the three alloys, although the NbC number density varied significantly. This could be explained by the following. In alloy L, due to the absence of precipitation, the recrystallization rate was significantly higher than this in alloys $\mathrm{M}$ and $\mathrm{H}$. Therefore, several stages of recrystallisation might have taken place in alloy $\mathrm{L}$ leading to significant grain refinement (the grain size decreased by about 26 times from the solution 
treated to the deformed condition). In alloy $\mathrm{M}$, due to a maximum of the $\mathrm{NbC}$ number density, the recrystallisation proceeded at a lower rate but the grain growth was also significantly retarded. Therefore, the grain refinement in alloy $M$ showed a middle value (the grain size decreased by 5 times from the solution treated to the deformed condition). In alloy $\mathrm{H}$, due to a maximum of the microalloying element content, the recrystallization rate was the slowest. Therefore, the grain refinement in alloy $\mathrm{H}$ was the lowest (the grain size decreased by 2 times from the solution treated to the deformed condition) and the stress-strain curve (Fig. 3) showed a relatively moderate softening compared to alloys $\mathrm{L}$ and $\mathrm{M}$. The recrystallisation retardation in alloy $\mathrm{H}$ did not lead to an increased grain size after deformation due to the initial grain size (after heating) being the lowest. A more detailed investigation of DRX in these alloys is required to support these explanations.

Table 2 Dependence of microstructural parameters and microhardness on TMP schedule

\begin{tabular}{|c|c|l|c|c|c|c|}
\hline $\begin{array}{c}\text { Alloy } \\
\text { type }\end{array}$ & $\begin{array}{c}{[\mathrm{Nb}+\mathrm{C}],} \\
\text { wt \% }\end{array}$ & $\begin{array}{c}\text { TMP } \\
\text { schedule, }{ }^{\circ} \mathrm{C}\end{array}$ & $\begin{array}{c}\text { Grain size, } \\
\mu \mathrm{m}\end{array}$ & $\begin{array}{c}\text { NbC size, } \\
\mathrm{nm}\end{array}$ & $\begin{array}{c}\text { NbC number } \\
\text { density, } \times 10^{5} \mathrm{~mm}^{-2}\end{array}$ & $\mathrm{HV}$ \\
\hline \multirow{3}{*}{$\mathrm{L}$} & \multirow{3}{*}{0.371} & 1250 hold & $500 \pm 100$ & no & no & $114 \pm 7$ \\
\cline { 3 - 7 } & & 1075 deform & $19 \pm 10$ & no & no & $151 \pm 7$ \\
\cline { 3 - 7 } $\mathrm{M}$ & \multirow{3}{*}{0.965} & 1075 hold & $92 \pm 20$ & no & no & $124 \pm 8$ \\
\hline & & 1250 hold & $90 \pm 20$ & $337 \pm 150$ & 0.05 & $131 \pm 10$ \\
\cline { 3 - 7 } & & 1075 deform & $18 \pm 10$ & $127 \pm 10$ & 13.1 & $184 \pm 8$ \\
\hline \multirow{3}{*}{$\mathrm{H}$} & \multirow{3}{*}{1.607} & 1250 hold & $27 \pm 10$ & $217 \pm 20$ & 4.2 & $164 \pm 8$ \\
\cline { 3 - 7 } & & 1075 deform & $22 \pm 10$ & $204 \pm 5$ & 7.2 & $190 \pm 4$ \\
\cline { 3 - 7 } & & 1075 hold & $31 \pm 10$ & $237 \pm 10$ & 6.5 & $180 \pm 7$ \\
\hline
\end{tabular}

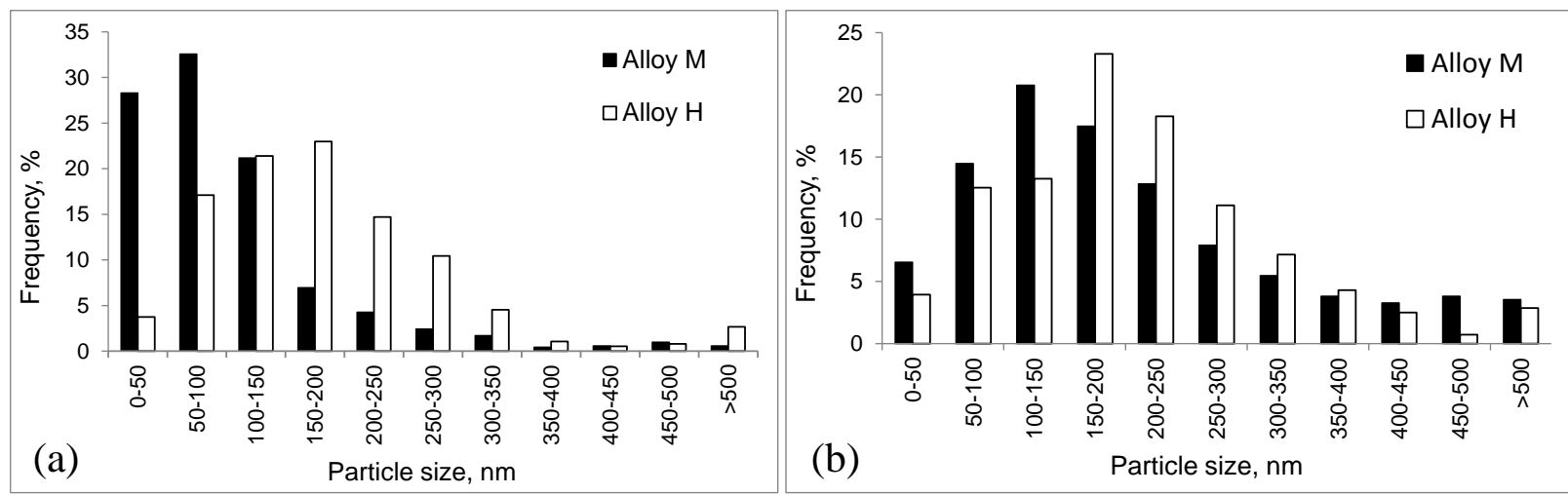

Fig. $6 \mathrm{NbC}$ particle size distributions for alloys $\mathrm{M}$ and $\mathrm{H}$ after (a) deformation and (b) holding.

During holding after deformation the grain growth took place, which was accompanied by the particle coarsening and a decrease in the particle number density. The grain growth was the largest in alloy $\mathrm{L}$, due to the absence of precipitation. The grain growth was similar in alloys $\mathrm{M}$ and $\mathrm{H}$, although the $\mathrm{NbC}$ number density after deformation was higher in alloy $\mathrm{M}$ than that in alloy $\mathrm{H}$. Obviously, a larger content of solid solutes and atom clusters, which might be expected in alloy $\mathrm{H}$ compared to $\mathrm{M}$, contributed to the grain growth retardation in this alloy.

For all the studied TMP conditions microhardness was higher for a more highly microalloyed material (Table 2), due to grain refinement, solid solution and precipitation strengthening mechanisms. However, the relative strengthening effect after deformation in alloy $\mathrm{M}$ compared to $\mathrm{L}, \Delta \mathrm{HV}_{\mathrm{M}-\mathrm{L}} /\left([\mathrm{Nb}+\mathrm{C}]_{\mathrm{M}}-[\mathrm{Nb}+\mathrm{C}]_{\mathrm{L}}\right)=55.5$, was higher than this in alloy $\mathrm{H}$ compared to $\mathrm{L}, \Delta \mathrm{HV} \mathrm{H}_{\mathrm{L}-\mathrm{L}} /$ $\left([\mathrm{Nb}+\mathrm{C}]_{\mathrm{H}}-[\mathrm{Nb}+\mathrm{C}]_{\mathrm{L}}\right)=31.5$. This may indicate a higher strengthening increment from a larger number of smaller particles (alloy M) compared to a smaller number of larger particles (alloy $\mathrm{H}$ ), which corresponds to the earlier observed data in microalloyed steels [13]. After holding the microhardness decreased in all the three alloys, due to grain coarsening, recovery of substructure 
and particle coarsening. However, the softening in alloy $\mathrm{H}$ was lower, compared to $\mathrm{M}$, due to much lower variation in the $\mathrm{NbC}$ number density in alloy $\mathrm{H}$.

\section{Summary}

Preliminary study of microstructure development in Ni-30Fe-Nb-C alloys during TMP has shown the following. The average grain size in a more highly microalloyed material varied to a lower extent during TMP, due to a decrease in recrystallisation and grain growth rates with an increase in microalloying element content. The critical and peak stresses for DRX increased with an increase in microalloying element content. $\mathrm{NbC}$ precipitates were more effective in retarding recrystallisation than $\mathrm{Nb}$ and $\mathrm{C}$ solute atoms. Precipitate coarsening resulting in a decrease in the grain boundary pinning effect and grain growth, led to a decrease in strength. However, the strength decrease was less pronounced in a more highly microalloyed material.

\section{Acknowledgement}

The authors are thankful to Prof. Hatem Zurob, McMaster University, Canada, for providing materials and to ARC and BSL (LP110100231) for financial support of the project. SEM was carried out using FEGSEM JSM 7001F microscope (LE0882813) at the UoW EMC.

\section{References}

[1] G.E. Dieter, Mechanical Metallurgy, McGraw-Hill Book Company, London, 1998.

[2] P.J. Hurley, P.D. Hodgson, B.C. Muddle, A study of deformation substructures in austenite using a model Ni-30 wt.\% Fe alloy, Scripta Materialia, 45 (2001) 25-32.

[3] A.S. Taylor, P. Cizek and P.D. Hodgson, Comparison of 304 stainless and Ni-30 wt\% Fe as potential model alloys to study the behaviour of austenite during thermomechanical processing, Acta Materialia, 59 (2011) 5832-5844.

[4] H. Beladi, P. Cizek and P.D. Hodgson, New insight into the mechanism of metadynamic softening in austenite, Acta Materialia, 59 (2011) 1482-1492.

[5] O. Kwon, A.J. DeArdo, Interactions between recrystallization and precipitation in hot-deformed microalloyed steels, Acta Metallurgica et Materiealia 39(4) (1991) 529 - 538.

[6] H.S. Zurob, G. Zhu, S.V. Subramanian, G.R. Purdy, C.R. Hutchinson and Y. Brechet, Analysis of the effect of $\mathrm{Mn}$ on the recrystallization kinetics of high $\mathrm{Nb}$ steel: an example of physicallybased alloy design, ISIJ Int. 45(5) (2005) 713 - 722.

[7] C.R. Hutchinson, H.S. Zurob, C.W. Sinclair and Y.J.M. Brechet, The comparative effectiveness of $\mathrm{Nb}$ solute and $\mathrm{NbC}$ precipitates at impeding grain-boundary motion in $\mathrm{Nb}$ steels, Scripta Materialia, 59 (2008) 635 - 637.

[8] S. Vervynckt, K. Verbeken, P. Thibaux, Y. Houbaert, Recrystallization-precipitation interaction during austenite hot deformation of a $\mathrm{Nb}$ microalloyed steel, Materials Science and Engineering A 528 (2011) 5519 - 5528.

[9] C.L. Miao, C.J. Shang, H.S. Zurob, G.D. Zhang, and S.V. Subramanian, Recrystallization, precipitation behaviors, and refinement of austenite grains in high $\mathrm{Mn}$, high $\mathrm{Nb}$ steel, Metallurgical and Materials Transactions A 43 (2012) 665 - 676.

[10] B. Feng, Effect of $\mathrm{Ti}$ and $\mathrm{Ti}-\mathrm{Nb}$ on the stability of the austenite grain structure and austenite to ferrite transformation characteristics in C-Mn steel under hot rolling conditions, $\mathrm{PhD}$ Thesis, University of Wollongong, 1991.

[11] R. P. de Siqueira, H. R. Z. Sandim and D. Raabe, Particle stimulated nucleation in coarse-grained ferritic stainless steel, Metallurgical and Materials Transactions A, 44 (2013) 469 - 478.

[12] H.S. Zurob, Effects of precipitation, recovery and recrystallization on the microstructural evolution of the microalloyed austenite, PhD Thesis, McMaster University, 2003.

[13] T. Gladman, The Physical Metallurgy of Microalloyed Steels, The Institute of Materials, London, 1997.

[14] A.J. DeArdo, Niobium in modern steels, International Materials Reviews, 48(6) (2003) 371 402. 